\title{
Combustion and Spectral Methods for Quantifying Carbon and Nitrogen Concentrations in Pacific Northwest Douglas-Fir Forest Soils
}

\author{
Christina Tonitto ${ }^{1} \&$ Ali Volkan Bilgili ${ }^{2,3}$ \\ ${ }^{1}$ Cornell International Institute for Food, Agriculture and Development, Cornell University, Ithaca, New York, \\ USA \\ ${ }^{2}$ Department of Crop and Soil Science, Cornell University, Ithaca, New York, USA \\ ${ }^{3}$ Department of Soil Science and Plant Nutrition, Harran University, Sanliurfa, Turkey \\ Correspondence: Christina Tonitto, Cornell International Institute for Food, Agriculture and Development, \\ Cornell University, Ithaca, New York 14853, USA. E-mail: ctonitto@cornell.edu; ctonitto@gmail.com
}

Received: March 9, 2016 Accepted: April 20, 2016 Online Published: May 15, 2016

doi:10.5539/jas.v8n6p8 URL: http://dx.doi.org/10.5539/jas.v8n6p8

\begin{abstract}
Traditional combustion methods for assessing soil carbon $(\mathrm{C})$ and nitrogen $(\mathrm{N})$ stocks are time consuming and expensive; visible and near-infrared (VNIR) methods offer a quick and inexpensive alternative for establishing soil $\mathrm{C}$ and $\mathrm{N}$ concentrations. We compared combustion and spectral methods for quantifying soil carbon and nitrogen concentrations. We sampled organic and mineral soil horizons in managed and old-growth Douglas-fir (Pseudotsuga menziesii) forests in western Oregon. We applied combustion methods to determine total soil carbon and nitrogen concentrations of these samples. We then applied VNIR methods to derive a reference spectral library for analyzing Pacific Northwest (PNW) andesitic forest soils. Our spectral analysis confirmed that visible range spectra (especially in the $650-750 \mathrm{~nm}$ range) are the most useful for distinguishing differences in sample soil organic matter content. Our results provide a robust calibration model for applying spectral analysis combined with Partial Least Square Regression (PLSR) to quantify carbon and nitrogen stocks in PNW Douglas-fir forest soils. Model validation resulted in $\mathrm{R}^{2}$ values ranging from 0.92 to 0.95 for $\mathrm{C}$ and from 0.73 to 0.84 for $\mathrm{N}$.
\end{abstract}

Keywords: Douglas-fir, Pacific Northwest, soil carbon, soil nitrogen, VNIR

\section{Introduction}

Awareness of the rate at which anthropogenic activities alter global carbon (C) (Marland, Boden, Andres, Brenkert, \& Johnston, 2002) and nitrogen (N) (Vitousek et al., 1997; Galloway \& Cowling, 2002) dynamics has led to widespread interest in modeling and monitoring global carbon (e.g. Solomon et al., 2007; IPCC, 2014) and nitrogen (e.g. International Nitrogen Initiative, http://initrogen.org, founded 2003) cycles. In particular, policy initiatives aimed at reducing net greenhouse gas emissions, such as California Assembly Bill 32, the Regional Greenhouse Gas Initiative (RGGI) and the Kyoto Protocol, promote interest in quantifying C stored in managed landscapes. Due to significant soil organic matter (SOM) stocks in forest soils and evidence of a seasonal carbon sink in the northern hemisphere (Fung, Tucker, \& Prentice, 1987; Pacala et al., 2001; Goodale et al., 2002; Fahey et al., 2010), temperate and boreal forest ecosystems have received particular attention from carbon researchers. Tools for quantifying SOM stocks, including $\mathrm{C}$ and $\mathrm{N}$ content, can support policy initiatives aimed at increasing $\mathrm{C}$ storage, can provide data for calibrating and validating models of $\mathrm{C}$ and $\mathrm{N}$ cycling, and can facilitate the monitoring of soil fertility in managed forest ecosystems.

Forests of the Pacific Northwest (PNW) demonstrate significant soil C storage potential. Sun et al. (2004) reported mineral soil C stocks ranging from $8-36 \mathrm{~kg} \mathrm{C} \mathrm{m}^{-2}$ (to a depth of $100 \mathrm{~cm}$ ) and forest floor $\mathrm{C}$ of $0.5-1.2 \mathrm{~kg}$ $\mathrm{C} \mathrm{m}^{-2}$ across 13 study sites in the PNW. Similarly, Hudiburg et al. (2009) quantified the significant potential for $\mathrm{C}$ accumulation in forests of the PNW and Hutyra, Yoon, and Alberti (2011) report even urban C stocks in the PNW exceed average U.S. forest carbon stocks.

However, forests $\mathrm{C}$ storage potential is not uniform across stand age. Landscape-scale forest literature emphasizes the proliferation of different-aged stands in the PNW (Franklin \& Forman, 1987; Li, Franklin, Swanson, \& Spies, 1993), the consequent creation of a mosaic of habitat edges in these managed forests (Chen, 
Franklin, \& Spies, 1992, 1993), and the change in ecosystem properties along stand edges (Griffiths \& Swanson, 2001). This mosaic of different-aged forest stands varies in its potential to sequester carbon, as demonstrated by the range of mineral soil $\mathrm{C}$, forest floor $\mathrm{C}$ and soil respiration observed across different aged stands by Sun et al. (2004). In a landscape of diverse forest management, accurate quantification of soil carbon stocks for monitoring policy initiatives will combine observational and model analysis.

Because soil properties are extremely variable in time and space (e.g. Burrough, 1983), accurately quantifying variation in soil element distribution requires intensive sampling. Soil sampling incurs significant time and monetary costs and is destructive in nature. In order to verify carbon accounting policy objectives, better tools are needed to quantify the spatial distribution of carbon in forest ecosystems (Fahey et al., 2010).

Relative to combustion analysis methods, spectral methods such as visible and near-infrared (VNIR) and mid-infrared analysis represent a promising methodology for assessing soil properties (e.g. Ben-Dor \& Banin, 1995a, 1995b; Chang, Laird, Mausbach, \& Hurburgh, 2001). The relative ease and inexpensive nature of applying spectral methods make them a possible tool for rapid assessment of soil carbon storage. Spectral methods have been applied with good accuracy to forest (Ludwig, Khanna, Bauhus, \& Hopmans, 2002; Terhoeven-Urselmans et al., 2006; Sankey, Brown, Bernard, \& Lawrence, 2008; Vasques, Grunwald, \& Sickman, 2008) and agricultural soils (Idowu et al., 2008; Bilgili, van Es, Akbas, Durak, \& Hively, 2010), and are increasingly applied in precision agriculture (Rossel \& McBratney, 1998; Bilgili, Akbas, \& van Es, 2011). Building a robust spectral library requires access to soil samples that have been analyzed with traditional laboratory techniques and demonstrate variation in soil properties (Shepherd \& Walsh, 2002; Brown, Shepherd, Walsh, Mays, \& Reinsch, 2006).

Creating spectral reference libraries is an important first step toward developing simple techniques for rapid soil assessment. Once reference libraries are established, spectral analysis is a relatively quick and inexpensive method for soil analysis. Tools that facilitate our ability to monitor soil properties have the potential to significantly improve our understanding of the effect of management practices on soil formation and soil $\mathrm{C}$ storage. We examined the potential for VNIR methods to serve as such a tool in PNW Douglas-fir ecosystems. In this paper we report a comparison of combustion and spectral methods for quantifying element stocks in andesitic soils. First, soils were analyzed for total soil C and N using combustion methods. Subsequently, we applied VNIR analysis to this spatially distributed soil data set to create a spectral database for quantifying soil C and $\mathrm{N}$ stocks. Our analysis included rigorous model validation using independent data not used in model development and calibration. In addition, we assessed whether VNIR methods would be robust if limited soil samples are available, by testing the accuracy of models developed from aggregated soil horizon spectral data and by testing the accuracy of models when applied to different aged stands.

\section{Methods}

\subsection{Site Characteristics}

Old-growth and harvested Douglas-fir-dominated stands were studied at the H. J. Andrews Experimental Forest in the western Cascades of Oregon, United States. Study site soils are Andisols classified as Andic Dystrochrepts (Dyrness, Norgren, Sollins, \& Vance-Borland, 1996). Andisols are highly productive soils formed from volcanic ash parent material and with a mineral profile that forms strong bonds with organic matter. The sampled watersheds are predominantly from the Carpenter soil series, with a surface horizon of dark brown gravelly sandy loam, lower horizons of dark brown gravelly sandy loam to loam, and virtually unlimited effective rooting depth due to deep, unconsolidated parent material (Dyrness \& Hawk, 1972). The mean monthly temperatures range from $0.6{ }^{\circ} \mathrm{C}$ in January to $17.8{ }^{\circ} \mathrm{C}$ in July; mean annual precipitation is $2257 \mathrm{~mm}$ with $70 \%$ of rainfall occurring between November and March (Bierlmaier \& McKee, 1989). The selectively harvested stand (watershed 7 or W7) is a 15.4 ha drainage and the old-growth stand (watershed 8 or W8) is a 21.5 ha drainage. The harvested stand drains at an elevation of $940 \mathrm{~m}$ and the old-growth stand at $995 \mathrm{~m}$ above sea level. An east-west transect was established at $1060 \mathrm{~m}$ elevation in the old-growth stand and at $1040 \mathrm{~m}$ elevation in the harvested stand. The watersheds include slopes with a $15-45 \%$ grade, and south and southeast aspects. The stands share a border, with the harvested stand lying to the west of the old-growth stand. The selectively harvested stand was cut in 1974, broadcast burned in 1975, and planted with Douglas-fir seedlings in 1976. Samples were collected in the summer of 1997, when the harvested stand was a 21-year-aged stand. Analysis of fire history concluded that the old-growth stand contains individuals up to 450 years old (Heyerdahl, Swanson, Berry, \& Agee, 1994). 


\subsection{Field Sampling}

Organic and mineral soil samples were collected at $2 \mathrm{~m}$ intervals along $256 \mathrm{~m}$ linear transects. In both stands, location ' $0 \mathrm{~m}$ ' corresponds to the plot along the edge shared by the old-growth and harvested stands. As a result, higher plot location values indicate farther distance in meters from the stand boundary. The old-growth stand plot numbers increase from west to east, while the harvested stand plot numbers increase from east to west.

At each sampling location the litter layer was removed, an organic soil core was taken across the entire depth of the organic soil horizon, and a $15 \mathrm{~cm}$ deep mineral soil sample was extracted. The upper organic soil was sampled with a $15 \mathrm{~cm}$ deep bulb planter and deeper soils where sampled with a $30 \mathrm{~cm}$ deep, $2 \mathrm{~cm}$ diameter corer. In the field, soil samples were stored in Ziploc ${ }^{\circledR}$ plastic bags in a cooler with ice. Soil samples were air dried until they attained a constant weight and subsequently passed through a $2 \mathrm{~mm}$ sieve. Fine roots that filtered through the sieve were removed from each sample using tweezers.

\subsection{Element Analysis}

Soil samples were ground in glass scintillation vials using stainless steel rods; mineral and organic soil replicates were ground separately. Organic and mineral soil samples were combusted to analyze total carbon and nitrogen concentration on a Perkin-Elmer 2400 Series II CHNS/O Analyzer (Waltham, MA). The weight of sample tins ranged from 17-28 $\mathrm{mg}$ for organic soil samples and from 30-50 mg for mineral soil samples. Error analysis was conducted for each sample type by taking subsamples from a single soil sample. Analytic organic, pine needle, or peach leaf standards were run every 10 samples to confirm autoanalyzer precision. Replicates were run every 5 samples to test data repeatability.

\subsection{Statistical Analysis}

We calculated summary statistics for total soil carbon and nitrogen concentrations determined using combustion methods. We calculated sample mean, standard deviation, and standard error and compared summary statistics across harvested and old-growth stands using t-test analysis. The relationship between sample total carbon and nitrogen concentration was assessed using correlation analysis.

The spatial distribution of total carbon and nitrogen concentrations was analyzed using autocorrelation and cross-correlation analysis (Wei, 1990). We tested the data series for stationarity using a power transformation test; the smallest residual sums of squares occurred for $\lambda=1$, confirming that the data are stationary and that a variance stabilizing transformation is not warranted (Wei, 1990). Patterns in organic and mineral soil element concentrations were compared within a data series using the autocorrelation function (ACF, Appendix 2 Eq. A2.1) and across two different data series using the cross-correlation function (CCF, Appendix 2 Eq. A2.2) analyses (Wei, 1990). The ACF equation tests for patterns of correlation among adjacent sample points within a single data set. An extension of the ACF equation, the CCF equation tests for such patterns across two separate data sets. Autocorrelation significance at a $95 \%$ confidence level is defined as values of the autocorrelation or cross-correlation coefficient (Equation A2.1, A2.2) that fall outside the region defined by $\pm 2 / \sqrt{n}$ (Wei, 1990). The value of an autocorrelation analysis depends on dataset length, with longer transects allowing for autocorrelation analysis of samples separated by longer distances, or lag, intervals. In this study, sample collection occurred at $2 \mathrm{~m}$ intervals along $256 \mathrm{~m}$ transects, allowing for the comparison of autocorrelation for sampling locations separated by $2-40 \mathrm{~m}$. For the $256 \mathrm{~m}$ transect studied, a lagged spatial analysis included 100 data pairs at the largest lag considered $(40 \mathrm{~m}$ ). All programs used for this analysis were written in Matlab (The MathWorks, Inc., Natick, MA).

\subsection{VNIR Analysis}

\subsubsection{Spectral Analysis}

Air-dried soils sampled for the combustion analysis were scanned using a FieldSpec Pro hyperspectral sensor (Analytical Spectral Devices, Inc., Boulder, CO: ASD, 1997). Absolute reflectance (decimal percent) of samples was recorded over the 350 to $2500 \mathrm{~nm}$ range at a 1-nm spectral resolution, yielding a total of 2150 data points per spectrum. Soil samples were placed into $4 \mathrm{~cm}$ diameter optical quality petri dishes and illuminated with a quartz tungsten halogen lamp light source held inside a Muglight sensor attachment. Reflectance was recorded through the glass bottom of each dish with a constant angle ( $55^{\circ}$ from horizontal) at a distance of $4 \mathrm{~cm}$ from the sensor. To avoid possible spectral differences originating from particle size variation within a soil sample, after five consecutive readings the sample was rotated $90^{\circ}$ and five additional readings were collected. Sensor calibration was performed using three standards: Spectralon (white spectra), kaolinite, and soil with known spectral characteristics. The white reference sample was run every 20-30 samples to check for machine accuracy; if spectral drift was noticed the lens was cleaned and a new baseline was established. The kaolinite soil reference 
samples were re-sampled at the end of each sampling day. Analysis was conducted making sure no light escaped through the soil dish.

Conversion of spectra to ASCII was conducted using ViewSpec Pro (Analytical Spectral Devices, Inc., Boulder, CO). We used S-PLUS (TIBCO Software Inc., Palo Alto, CA) to create a master data file with one representative reflectance spectrum per soil sample. Representative reflectance spectra were created for each spectral band by averaging the ten readings obtained at two different positions per sample. In order to identify patterns in the spectral results, we applied a principal components analysis (PCA) to the raw reflectance results using all VNIR spectral bands prior to model calibration. We analyzed each data set separately to allow for a detailed characterization of the spectra. Using PCA allows us to transform the data set into linearly uncorrelated variables - the principal components (PCs). The transformation is defined such that the first PC accounts for the largest variability in the data set. The PC with the highest coefficients or loadings contributes more information toward characterizing the data set. The goal of applying PCA is to reduce the number of relevant variables for characterizing the data.

\subsubsection{Statistical Model Calibration and Validation}

The accuracy of spectral methods is affected by factors such as sample range, calibration model quality, and calibration technique. We calibrated soil reflectance to soil properties using partial least squares regression (PLSR) analysis. This method quantifies the relationship between two data matrices, $\mathrm{X}$ and $\mathrm{Y}$, by a linear multivariate model and is widely used in VNIR reflectance spectroscopy (Daniel, Tripathi, Honda, \& Apisit, 2004). In this study $X$ was the soil reflectance and $Y$ was the soil property established with combustion methods. Unlike multiple linear regression (MLR), PLSR can handle data with strong collinearity in the independent (X) variables, which may occur with higher frequency relative to the observations (Y). Vasques et al. (2008) compared the accuracy of different calibration techniques (stepwise MLR, PCA, PLSR, classification and regression tree (CART)) as well as different pre-processing techniques for the estimation of soil $\mathrm{C}$ and found that all approaches produced similar results with very successful estimation accuracy. However, the best result was obtained using the PLSR method. PLSR models a linear relationship between variable and reflectance spectra, while models such as multivariate adaptive regression splines (MARS) or CART are used to model a nonlinear relationship. The linear relationship in our soil C and N spectral analysis suggests PLSR is the best model for our system (Vasques et al., 2008). Taking the first derivative of spectra did not improve our estimations (data not shown), rather the raw spectra provided the best results.

In PLSR applications, selection of the number of latent variables is critical to prevent over- or under-fitting the data, which would create models with poor predictive capability. We robustly calibrated the PLSR model using leave-one-out cross-validation (LOOCV). In this method the data is divided into subsets. The calibration model is constructed using all but one subset, and the model is validated against the removed subset. This process is repeated with a different subset removed for model testing in each iteration. We applied LOOCV calibration and cross-validation techniques using only $70 \%$ of the data set. In addition to cross-validation, model accuracy was assessed through validation using the remaining $30 \%$ of the data set. Random numbers were generated in Excel for this analysis. The PLSR analysis was performed on the ASCII-formatted spectral data using the Unscrambler V.8.0.5 (CAMO, Oslo, Norway).

In addition, we tested the predictive ability of models developed using data from aggregated soil horizons by developing calibration models using spectral outcomes from both the organic and mineral horizons in each stand. Lastly, we tested whether a model calibrated for a particular stand management had predictive power across different stands. We used a model calibrated in the harvested stand to predict element distribution in the old-growth stand as well as the converse scenario.

\subsubsection{Prediction Accuracy}

In our validation analysis, model accuracy was evaluated using: i) the coefficient of determination $\left(R^{2}\right)$ between measured and predicted sample values, ii) the root mean square error of prediction $\left(R M S E P=\sqrt{\sum_{i=1}^{n}\left[\left(Y_{\text {prediced }}-Y_{\text {measured }}\right)^{2} /(n-1)\right]}\right)$ based on the difference between measured and predicted values, and iii) the ratio of standard deviation to RMSEP $(R P D=$ Standard Deviation $/ R M S E P)$. An $\mathrm{R}^{2}>0.75$ and RPD $>2.5$ suggests the model is accurate and reliable; spectral results with RPD $>2$ are categorized as reliable, while a range of $1.5<\mathrm{RPD}<2$ suggests the spectral analysis is promising, but with inaccuracies (Chang et al., 2001; Dunn, Beecher, Batten, \& Ciavarella, 2002; Shepherd \& Walsh, 2002). 


\section{Results}

\subsection{Combustion Analysis and Summary Statistics}

As expected, total carbon and nitrogen content was abundant in organic soil and low in mineral soil (Table 1). There was insufficient organic soil present at some sampling locations to gather a sample, with significant gaps in the presence of a distinct organic soil horizon in the harvested stand. Total soil $\mathrm{C}$ and $\mathrm{N}$ concentrations were normally distributed. T-test analyses comparing $\mathrm{C}$ and $\mathrm{N}$ concentration between harvested and old-growth stands showed differences were statistically significant at the $\alpha=0.05$ level $(p<0.001$ for all comparisons except mineral soil $\% \mathrm{~N}$ with $\mathrm{p}=0.026$ ).

A correlation analysis of within sample $\mathrm{C}$ versus $\mathrm{N}$ concentration confirmed the notion of a constant $\mathrm{C}: \mathrm{N}$ ratio commonly applied when modeling surface soil horizons. Correlation coefficient results demonstrated strong positive correlation between sample $\mathrm{C}$ and $\mathrm{N}$ concentration in organic soil of the harvested stand $(\mathrm{r}=0.74, \mathrm{n}=$ 89), mineral soil of the harvested stand $(r=0.75, n=129)$, organic soil of the old-growth stand $(r=0.84, n=$ $125)$, and mineral soil of the old-growth stand $(\mathrm{r}=0.7, \mathrm{n}=129)$. There was no correlation between $\mathrm{C}$ and $\mathrm{N}$ concentration across organic and mineral soil horizons.

The distribution of total soil carbon and nitrogen concentrations varied widely around the mean over small spatial scales (Figures 1 and 2). This high-frequency change in $\mathrm{C}$ and $\mathrm{N}$ concentration suggests that there was variation at scales smaller than the scale of measurement. Given a standard error of the replicates that was one to three orders of magnitude smaller than the standard deviation in sample $\mathrm{C}$ and $\mathrm{N}$ concentrations, the observed meter-scale variation in carbon and nitrogen concentration exceeded the variation introduced by error in the combustion analysis methods (Table 1).

Soil $\mathrm{C}$ and $\mathrm{N}$ concentration did not exhibit a clear spatial pattern. In the harvested stand, mineral and organic soil $\mathrm{C}$ and $\mathrm{N}$ concentration showed less high-frequency variation, with a trend toward moderate, clumped troughs and isolated, elevated peaks (Figure 1). In the old-growth stand, organic and mineral soil $\mathrm{C}$ and $\mathrm{N}$ concentration varied drastically in adjacent plots, with values fluctuating above and below the mean across the entire stand (Figure 2). In both stands, the pattern of variation in $\mathrm{C}$ and $\mathrm{N}$ concentration was strongly correlated.

In mineral soil samples from the harvested stand, positive autocorrelation in $\mathrm{N}$ concentration occurred at 2 and 4 $m$ intervals, demonstrated by ACF values that exceeded the significance criteria, $r_{k}= \pm 2 / \sqrt{n}$. No significant autocorrelation was observed in the distribution of soil $\mathrm{C}$ and $\mathrm{N}$ concentration in the old-growth stand. Cross-correlation analysis did not uncover compelling patterns.

Table 1. Mean and standard deviation (SD) of carbon $(\% \mathrm{C})$ and nitrogen $(\% \mathrm{~N})$ concentrations for harvested and old-growth stands. Standard error (SE) of the replicates and sample mean C:N are reported. * Mean only includes plots for which there was a sample

\begin{tabular}{llllllllll}
\hline Site & Sample & \%C & SD & SE & \%N & SD & SE & C:N & n \\
\hline Harvested & Organic Soil $*$ & 22.80 & 11.26 & 0.58 & 0.61 & 0.30 & 0.001 & 38.2 & 89 \\
Harvested & Mineral Soil & 5.27 & 1.99 & 0.02 & 0.20 & 0.05 & 0.004 & 25.8 & 129 \\
\hdashline Old-growth & Organic Soil * & 29.03 & 10.40 & 0.98 & 0.68 & 0.20 & 0.020 & 42.9 & 126 \\
Old-growth & Mineral Soil & 6.11 & 1.81 & 0.16 & 0.19 & 0.05 & 0.004 & 34.1 & 129 \\
\hline
\end{tabular}



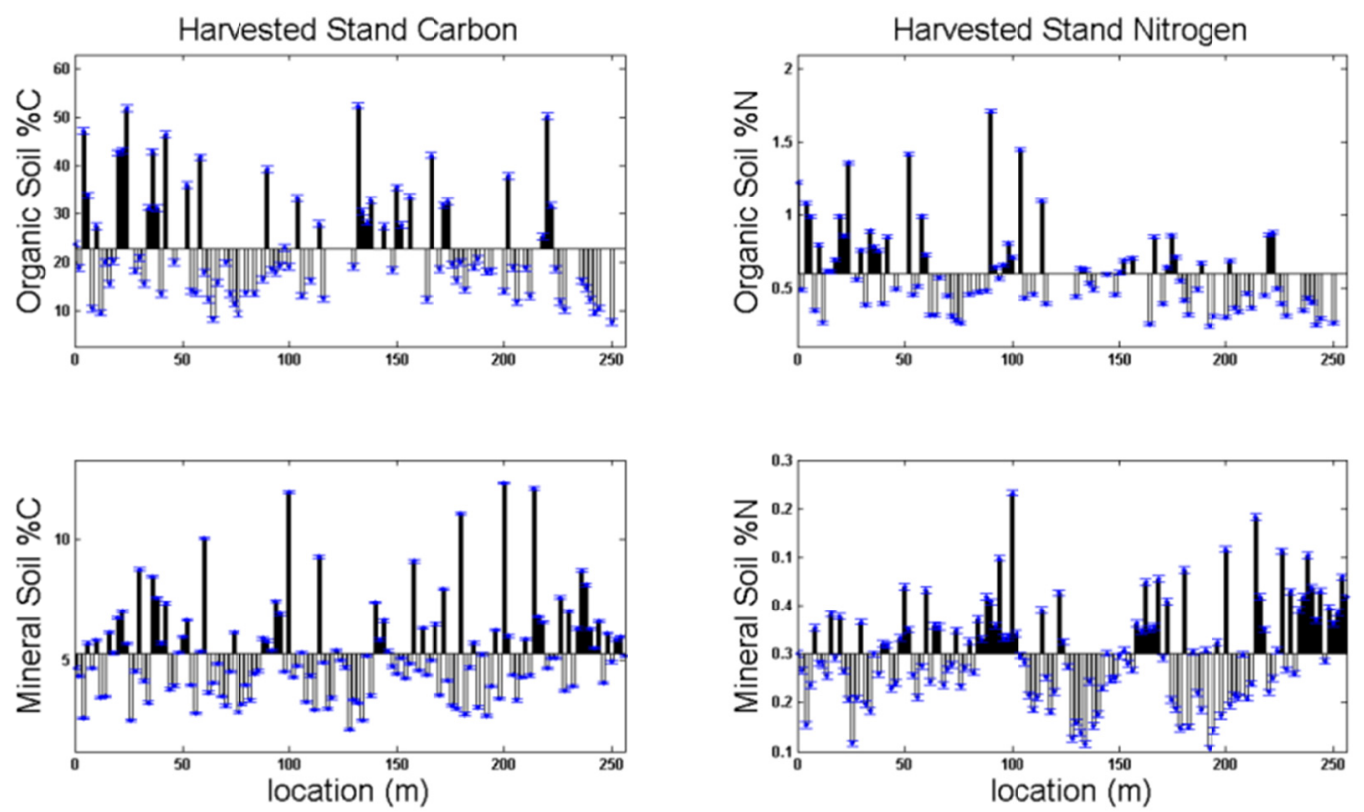

Figure 1. Distribution of total soil carbon and nitrogen concentrations around the mean value in the harvested stand

Note. Horizontal bars bound the standard error. Black bars are values above and white bars are values below the stand mean $\mathrm{C}$ or $\mathrm{N}$. Location $=0 \mathrm{~m}$ corresponds to the edge shared with the old-growth stand.
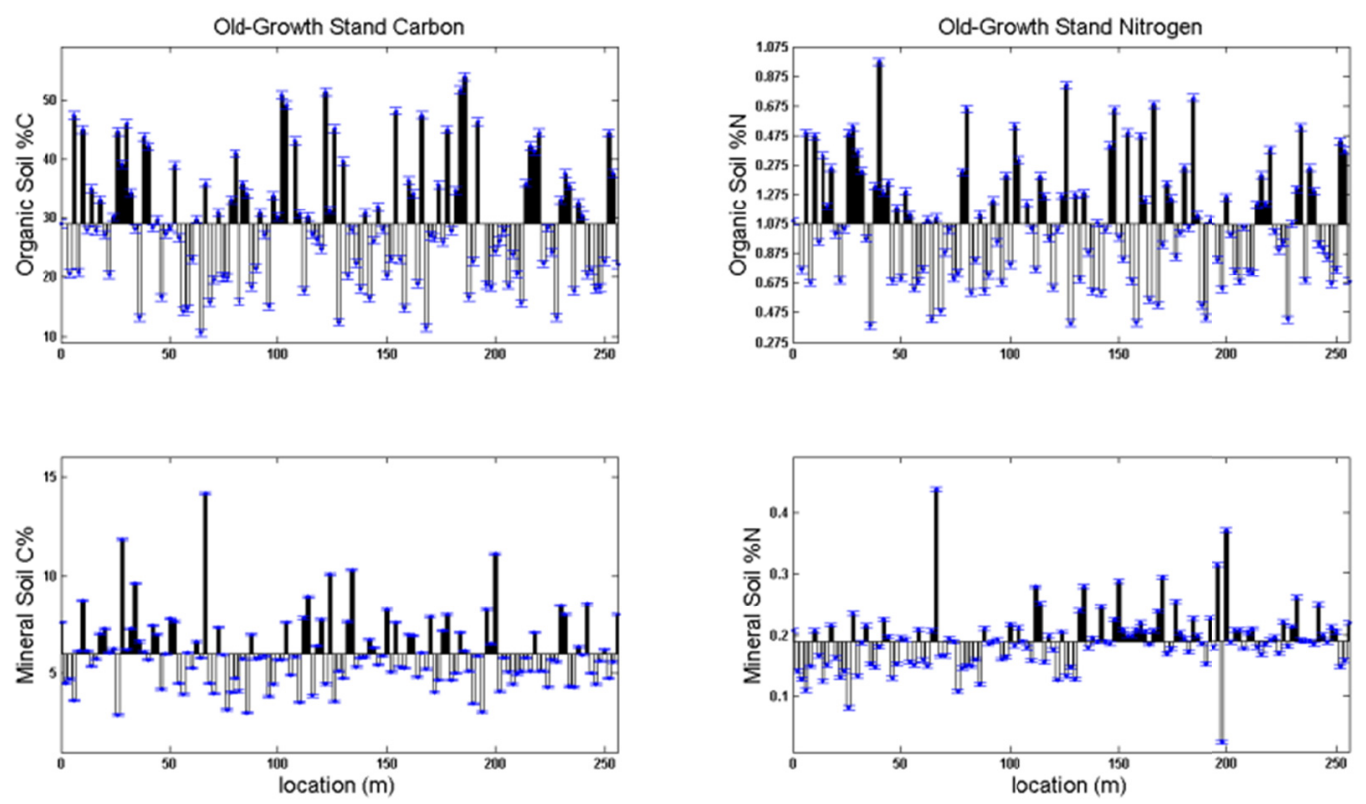

Figure 2. Distribution of total soil carbon and nitrogen concentrations around the mean value in the old-growth stand

Note. Horizontal bars bound the standard error. Black bars are values above and white bars are values below the stand mean $\mathrm{C}$ or $\mathrm{N}$. Location $=0 \mathrm{~m}$ corresponds to the edge shared with the harvested stand.

\subsection{VNIR Analysis}

3.2.1 Soil Reflectance Characteristics

Figure 3 shows the average raw reflectance spectra obtained in the visible and near infrared range (350 to 2500 
$\mathrm{nm}$ ) with a $1 \mathrm{~nm}$ spectral resolution; results are for organic and mineral soils from the harvested (W7) and the old-growth (W8) watersheds. There were three common absorption regions around 1400, 1900, and $2200 \mathrm{~nm}$ that are well-known absorption bands related to $\mathrm{OH}, \mathrm{H}$, and water molecules in clay minerals (Hunt, 1980; Ben-Dor \& Banin, 1995). In addition, there were clear spectral differences between the reflectance of mineral and organic soil samples. Organic soils demonstrated a lower reflectance in the visible range, resulting in a concave shape up to $700 \mathrm{~nm}$; the lower reflectance in the visible range is typically attributed to the characteristic darkness resulting from high organic matter content. The difference in spectral reflectance between organic and mineral soils was insignificant for wavelengths of 1000-1200 nm, but after $1250 \mathrm{~nm}$ organic soil samples showed a higher reflectance.

PCA results in Table 2 show the correlation of measured soil $\mathrm{C}$ and $\mathrm{N}$ with the first ten PCs for each data set. Significant $(\mathrm{p}<0.01)$ positive and negative correlation between the PCs and measured soil $\mathrm{C}$ and $\mathrm{N}$ were found for the first nine PC groupings, with the first two PCs explaining 98\% of the variance (Figure 4c) and PC2 demonstrating the highest occurrence of significant correlation with measurements.

In our analysis, PC2 separated the soil samples into two groups (Figures 4a and 4b). The mineral soil samples (shaded circles in Figures $4 \mathrm{a}$ and $4 \mathrm{~b}$ ) had a positive coefficient for PC2, while the organic soil samples (empty circles Figures $4 \mathrm{a}$ and $4 \mathrm{~b}$ ) had a negative coefficient. This indicates that the VNIRS-PCA method can separate soils based on their organic matter content. A plot of variable (wavelength) loading in PC2 showed that the highest positive loading occurred in the 650 to $750 \mathrm{~nm}$ wavelength (Figure 4d), indicating that reflectance of these spectral bands were affected most significantly by soil $\mathrm{C}$ and $\mathrm{N}$.

Table 2. Correlation coefficients from a PCA of spectral reflectance and measured soil C and N content. Results indicate coefficients for analysis of mineral and organic soil from the harvested stand (W7) and old-growth stand (W8)

\begin{tabular}{|c|c|c|c|c|c|c|c|c|c|c|c|}
\hline & & $\mathrm{PC} 1$ & $\mathrm{PC} 2$ & PC3 & PC4 & PC5 & PC6 & PC7 & PC8 & PC9 & PC10 \\
\hline \multirow[t]{2}{*}{ W7-mineral } & $\mathrm{C}$ & 0.15 & $-0.50 * *$ & $-0.27 * *$ & $-0.37 * *$ & $0.32 * *$ & -0.01 & -0.07 & $0.34 * *$ & -0.13 & -0.06 \\
\hline & $\mathrm{N}$ & $0.18^{*}$ & $-0.46^{* *}$ & -0.14 & $-0.35^{* *}$ & $0.39 * *$ & -0.14 & -0.11 & $0.49 * *$ & 0.09 & 0.09 \\
\hline \multirow[t]{2}{*}{ W7-organic } & $\mathrm{C}$ & $0.25 *$ & $-0.46^{* *}$ & -0.03 & -0.19 & -0.13 & $0.22 *$ & 0.18 & 0.14 & -0.05 & 0.15 \\
\hline & $\mathrm{N}$ & 0.14 & $-0.40 * *$ & -0.07 & $-0.21 *$ & -0.04 & -0.16 & $0.26^{*}$ & $0.26^{*}$ & -0.08 & 0.19 \\
\hline \multirow[t]{2}{*}{ W8-mineral } & $\mathrm{C}$ & $-0.32 * *$ & $-0.68 * *$ & $-0.19^{*}$ & $-0.33^{* *}$ & 0.05 & $0.20^{*}$ & -0.16 & 0.00 & $0.21 *$ & -0.07 \\
\hline & $\mathrm{N}$ & 0.07 & $-0.66 * *$ & -0.12 & -0.14 & -0.12 & $0.18^{*}$ & -0.17 & -0.13 & $0.25^{* *}$ & -0.17 \\
\hline \multirow[t]{2}{*}{ W8-organic } & $\mathrm{C}$ & $0.42 * *$ & $-0.60 * *$ & $0.45^{* *}$ & $-0.32 * *$ & $0.21 *$ & $0.24 * *$ & -0.02 & 0.05 & -0.04 & -0.03 \\
\hline & $\mathrm{N}$ & $0.35 * *$ & $-0.56 * *$ & $0.42 * *$ & -0.08 & -0.12 & $0.29 * *$ & -0.04 & 0.10 & -0.07 & -0.12 \\
\hline
\end{tabular}

Note. *: Significant at $\mathrm{p}<0.05$ level; **: Significant at $\mathrm{p}<0.01$ level.

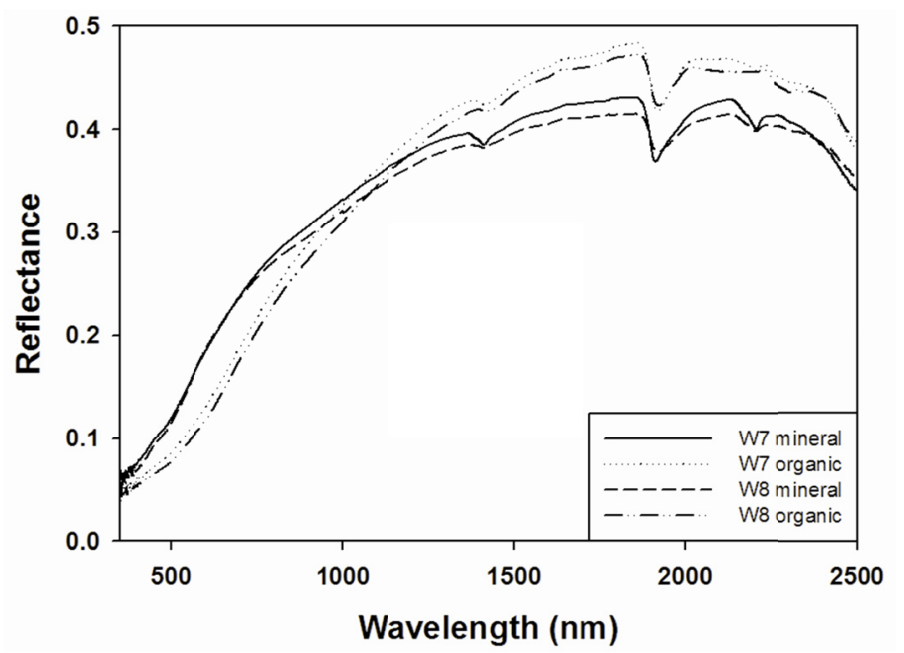

Figure 3. Average reflectance spectra in the VNIR range. Spectra are from analysis of organic and mineral soil samples in the harvested (W7) and old-growth (W8) stands 

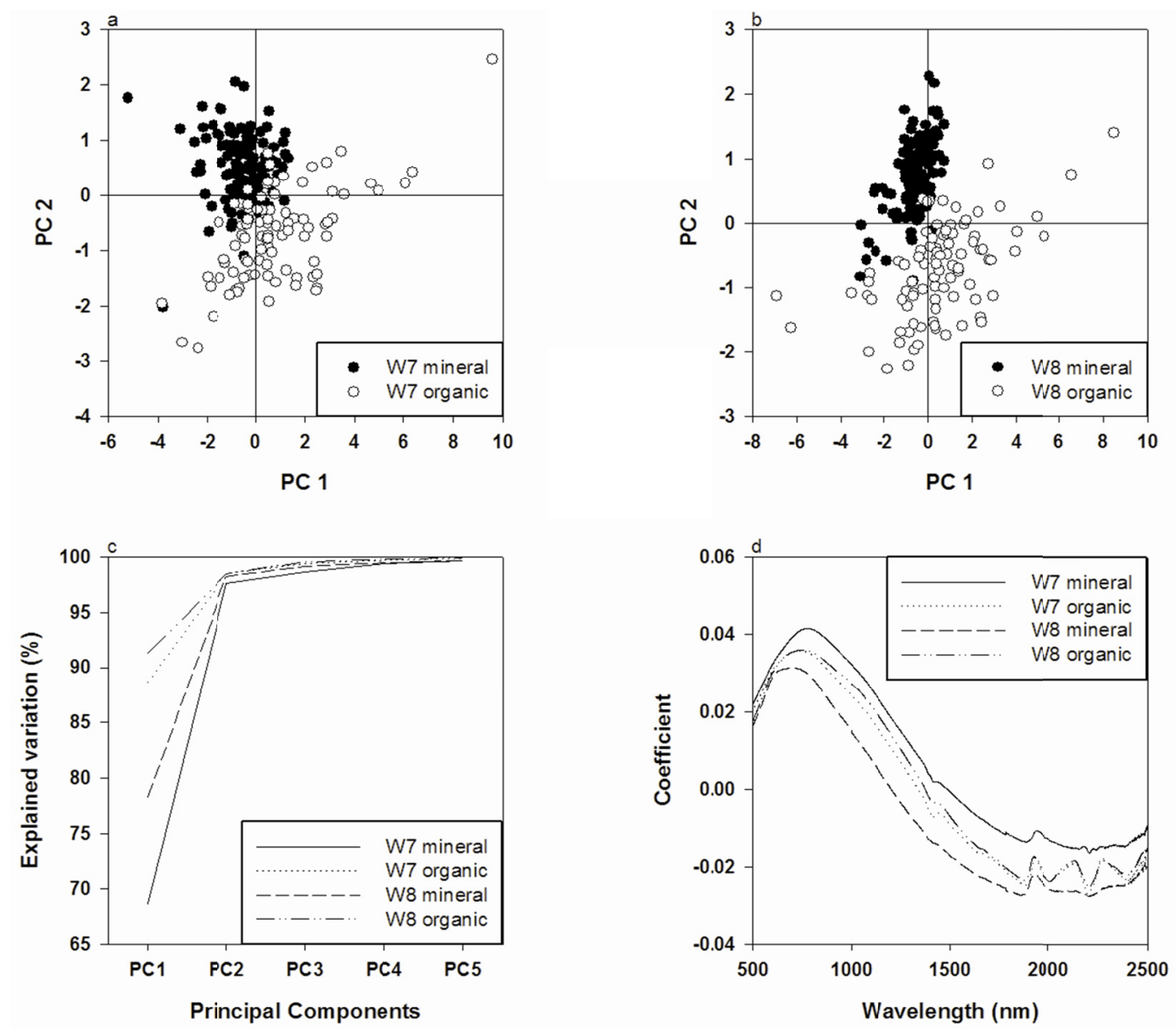

Figure 4. PCA results demonstrating grouping of organic and mineral soil properties in a) the score plot of PC1 and PC2 for the harvested watershed (W7) and b) the score plot of PC1 and PC2 for the old-growth watershed

(W8). Plot $4 \mathrm{c}$ shows the cumulative variance explained by the first five PCs. Plot $4 \mathrm{~d}$ shows the loading coefficients in $\mathrm{PC} 2$

\subsubsection{Model Calibration and Validation}

Table 3 outlines the validation results. For a given data set, estimation of model accuracy using cross-validation and independent validation approaches yielded very similar results. For model-data comparison within individual soil horizons, cross-validation resulted in $\mathrm{R}^{2}$ values ranging from 0.93 to 0.97 for $\mathrm{C}$ and from 0.75 to 0.89 for $\mathrm{N}$. The $\mathrm{R}^{2}$ values for the independent validation method ranged from 0.92 to 0.95 for $\mathrm{C}$ and from 0.73 to 0.84 for $\mathrm{N}$. The independent validation demonstrated $\mathrm{C}$ prediction under a specific stand management was accurate and reliable within a soil horizon, with RPD $>2.5$. Model prediction of total soil $\mathrm{N}$ was also reliable, with RPD values varying around 2 .

For models derived using the combined spectral outcomes from the organic and mineral horizons in each stand, this aggregated data had similar robust independent validation outcomes. The $\mathrm{R}^{2}$ values were $0.97,0.88,0.72$, and 0.69 for old-growth stand $\mathrm{C}$, old-growth stand $\mathrm{N}$, harvested stand $\mathrm{C}$, and harvested stand $\mathrm{N}$, respectively (Table 3). The RPD metric showed the model based on combined spectra was very accurate and reliable in the old-growth stand. In the harvested stand the model from combined spectra was slightly less reliable relative to a model based on specific soil horizon observations. Overall, model calibration using mixed-horizon soil samples were useful for predicting $\mathrm{C}$ and $\mathrm{N}$ concentration.

Tests of model performance when applied to stands with different management histories demonstrated model prediction of carbon was moderate, while prediction of nitrogen was poor; all cases resulted in $\mathrm{RPD}<1.5$, while $\mathrm{R}^{2}$ statistics showed stronger predictive capacity. When the harvested stand model was applied to predict carbon in the old-growth stand, model validation resulted in $\mathrm{R}^{2}=0.80$ for mineral soils and $\mathrm{R}^{2}=0.62$ for organic soils. 
When the old-growth model was applied to predict harvested stand carbon content, the validation showed an $\mathrm{R}^{2}$ $=0.72$ for mineral soils, but $\mathrm{R}^{2}=0.40$ for organic soils.

Table 3. Statistical assessment of model cross-validation and independent validation. Results show model validation for the harvested (W7) and old-growth (W8) stands. Within each stand category, model calibration was implemented for 1) combined organic and mineral soil samples, 2) organic samples only, or 3) mineral samples only

\begin{tabular}{|c|c|c|c|c|c|c|c|c|}
\hline \multicolumn{4}{|c|}{ Cross validation } & \multicolumn{5}{|c|}{ Independent Validation $\dagger$} \\
\hline \multirow{2}{*}{ Data Set } & \multirow{2}{*}{ Variables } & \multirow{2}{*}{$\mathrm{R}^{2}$} & \multirow{2}{*}{ RMSEP } & \multicolumn{2}{|c|}{ Calibration } & \multicolumn{3}{|c|}{ Validation } \\
\hline & & & & $\mathrm{R}^{2}$ & $\mathrm{SEC}^{\S}$ & $\mathrm{R}^{2}$ & RMSEP & $\mathrm{RPD}^{\alpha}$ \\
\hline \multirow[t]{2}{*}{ W7-combined } & $\mathrm{C}$ & 0.95 & 0.62 & 0.83 & 6.54 & 0.72 & 4.75 & 1.89 \\
\hline & $\mathrm{N}$ & 0.79 & 0.03 & 0.79 & 0.19 & 0.69 & 0.11 & 1.61 \\
\hline \multirow[t]{2}{*}{ W7-organic } & $\mathrm{C}$ & 0.93 & 2.93 & 0.95 & 2.35 & 0.92 & 3.32 & 3.54 \\
\hline & $\mathrm{N}$ & 0.75 & 0.15 & 0.86 & 0.11 & 0.75 & 0.14 & 1.94 \\
\hline \multirow[t]{2}{*}{ W7-mineral } & $\mathrm{C}$ & 0.94 & 0.66 & 0.97 & 0.30 & 0.92 & 0.62 & 3.35 \\
\hline & $\mathrm{N}$ & 0.83 & 0.03 & 0.83 & 0.02 & 0.81 & 0.02 & 2.07 \\
\hline \multirow[t]{2}{*}{ W8-combined } & $\mathrm{C}$ & 0.97 & 2.91 & 0.97 & 2.75 & 0.97 & 2.46 & 4.99 \\
\hline & $\mathrm{N}$ & 0.94 & 0.09 & 0.93 & 0.10 & 0.88 & 0.11 & 5.59 \\
\hline \multirow[t]{2}{*}{ W8-organic } & $\mathrm{C}$ & 0.97 & 2.62 & 0.95 & 2.21 & 0.95 & 2.53 & 3.96 \\
\hline & $\mathrm{N}$ & 0.89 & 0.09 & 0.89 & 0.06 & 0.84 & 0.10 & 2.16 \\
\hline \multirow[t]{2}{*}{ W8-mineral } & $\mathrm{C}$ & 0.94 & 0.61 & 0.95 & 0.33 & 0.93 & 0.74 & 3.20 \\
\hline & $\mathrm{N}$ & 0.75 & 0.03 & 0.59 & 0.03 & 0.73 & 0.04 & 1.70 \\
\hline
\end{tabular}

Note. $\dagger$ : Validation using samples independent of the calibration data set; $\$$ : Root Mean Square Error of Prediction; §: Standard Error of Calibration; $\alpha$ : Ratio of Deviation to Prediction (SD/RMSEP).

\section{Discussion}

\subsection{Carbon and Nitrogen Distribution}

Mean carbon and nitrogen content observed in this study was similar to Dyrness et al. (1996) H. J. Andrews experimental forest soil survey observations which resulted in mean element concentrations of $9.2 \% \mathrm{C}$ and $0.18 \% \mathrm{~N}$ for data averaged across stand ages. Our element analysis also overlapped with observations from a 70-100-year-aged stand that naturally regenerated following fire in the Siskiyou National Forest in western Oregon. This Siskiyou stand was sampled to observe soil variability, with resulting O-horizon element concentrations ranging from $13.1-51.6 \% \mathrm{C}$ and $0.25-1.6 \% \mathrm{~N}$ and the $0-15 \mathrm{~cm}$ mineral soil element concentration ranging from $2.5-13.5 \% \mathrm{C}$ and $0.09-0.34 \% \mathrm{~N}$ (Homann, Bormann, \& Boyle, 2001).

Relative to the old-growth stand, the harvested stand demonstrated a $20 \%$ reduction in carbon concentration and a $10 \%$ reduction in nitrogen concentration of the organic soil layer. A $14 \%$ reduction in mineral soil carbon concentration in the harvested stand relative to the old-growth stand was also observed. Various mechanisms could have caused the reduced soil $\mathrm{C}$ and $\mathrm{N}$ observed in the harvested stand, relative to the old-growth stand. Reduced soil $\mathrm{C}$ and $\mathrm{N}$ could result from the disturbance caused by harvesting, including forest biomass removal during the harvest resulting in reduced litter inputs, post-harvest broadcast burning of organic matter, or soil erosion following the harvest. In addition, reduced soil $\mathrm{C}$ and $\mathrm{N}$ in the harvested relative to the old-growth stand could have resulted from vegetation and environmental differences during stand succession. The open canopy of a regenerating stand creates a different microclimate (Chen et al., 1992, 1993), exposing the surface soils to different post-harvest decomposition conditions. The open canopy of a regenerating stand also supports different understory vegetation, a property that influences watershed $\mathrm{C}$ and $\mathrm{N}$ cycling. Post-harvest changes in soil organic matter have been documented in other temperate forest ecosystems. Klopatek (2002) found that $\mathrm{C}$ and $\mathrm{N}$ were lost from harvested Douglas-fir stands 20 and 40 years after harvest, while $\mathrm{C}$ and $\mathrm{N}$ were gained in old-growth stands. Johnson (1995) found carbon was preferentially lost from SOM relative to nitrogen, causing lower soil $\mathrm{C}: \mathrm{N}$ ratios relative to unharvested stands 8 years after a whole-tree clear-cut in northeastern U.S. hardwood forests. 
The observed variation lacking a distinct spatial pattern at the scale of sampling is consistent with Griffiths and Swanson (2001) work examining soil properties along the edge of different aged Douglas-fir stands. The fine-scale variation observed in this study is consistent with the high variation in soil $\mathrm{C}$ and $\mathrm{N}$ concentration observed in 70- and 100-year-old Douglas-fir forests of western Oregon, with coefficients of variation ranging from 20-30\% reported for $\mathrm{C}$ and $\mathrm{N}$ concentrations of the organic and mineral soil (Homann et al., 2001). The rapid change from soil $\mathrm{C}$ and $\mathrm{N}$ concentration peaks to troughs at the meter scale suggests that there is variation at finer spatial resolutions. Consistent with Burrough's (1983) notion that processes that act in a nested and spatially autocorrelated manner at large map scales may appear as a white noise (or random) process at other scales, the data hint at patterns over 50-100 meter lags. However a data series with larger spatial extent is necessary to address pattern formation at this scale.

\subsection{Soil Reflectance}

The maximum overall reflectance magnitude (albedo) of our sampled soils was $45 \%$, which is consistent with previous studies (e.g. Daniel et al., 2004; Summers, Lewis, Ostendorf, \& Chittleborough, 2011). As soil water content and organic matter increases, the overall reflectance decreases. Greater absorption of light was observed in organic soil samples relative to mineral soil samples (Figure 3); organic samples exhibit lower reflectance and higher absorbance in the visible and short NIR wavelength range (up to $900 \mathrm{~nm}$ ). Galvão and Vitorello (1998) as well as Jensen (2000) reported a greater amount of OM is associated with a greater absorption of incident energy, and therefore with a lower spectral reflectance. Similarly, Daniel et al. (2004) reported that organic matter reduced the reflectance in the 550 and $700 \mathrm{~nm}$ range. Our spectral trends are consistent with the organic matter spectral dynamics observed in the literature.

The spectral characteristics and PCA results from the visible spectral range demonstrated a consistent relationship to measured $\mathrm{C}$ and $\mathrm{N}$ concentrations. $\mathrm{PC} 2$ had significant negative correlation with measured carbon and nitrogen (Table 2). All wavelengths in the visible range had positive loadings with PC2, while PC2 had negative correlation with measured $\mathrm{C}$ and $\mathrm{N}$. Because high organic matter increases visible-range spectral absorption and reduces reflectivity, it is consistent for $\mathrm{PC} 2$, which is a grouping of visible range spectra, to have negative correlation with soil $\mathrm{C}$ and $\mathrm{N}$ content.

Our PC2 trends were consistent with the effect of soil organic carbon (SOC) trends observed in the literature. The highest positive loading was observed in the 650 to $750 \mathrm{~nm}$ wavelength (Figure 4d). This is consistent with results from Bartholomeus et al. (2008) that showed the highest correlation coefficients between SOC and 600 and $700 \mathrm{~nm}$ range wavebands. Vasques et al. (2008) reported wavelengths in the visible range, such as 430, 460, and $590 \mathrm{~nm}$, to be the most significant bands with the highest stepwise multiple linear regression coefficients for the estimation of soil carbon content.

\subsection{Application of Spectral Models}

The predictive capacity of VNIR methods is primarily dependent on the extent of the relationship between the soil property of interest and the spectral reflectance. Variables such as soil organic matter, carbon, soil texture, and iron are directly related to soil spectral characteristics and specific absorption bands within the VNIR wavelength range. Because SOM is directly correlated to spectral reflectance, our model has good predictive capability. Some soil properties are only indirectly related to soil spectra, such as cation-exchange capacity, and the success of VNIR in estimation of these variables is related to the degree of correlation of the variable with soil parameters that are directly related to soil spectra (Bilgili et al., 2010).

Our analysis showed that VNIR was well-suited to characterize the carbon and nitrogen content of PNW forests on andesitic soils. Organic and mineral soil carbon and nitrogen were successfully estimated using cross-validation and independent validation methods in both harvested and old-growth stands (Table 3). Based on the RPD metric, individual soil horizon calibration models were most accurate for estimating SOC in organic soils of the old-growth site (W8-organic), followed by organic soils of the harvested stand (W7-organic), mineral soils of the harvested stand (W7-mineral) and lastly in mineral soils of the old-growth site (W8-mineral). Model accuracy for nitrogen followed the same sequence as carbon, except model application to mineral soils of the harvested stand (W7-mineral) was slightly more accurate than that in organic soil of the harvested stand (W7-organic). A model calibrated using aggregated soil horizon spectra and observations (W7-combined, W8-combined) likewise resulted in good validation outcomes. Model validation showed reliable outcomes when applied to predict soils with a similar management history; however, model application to predict soil element concentration of different aged stands showed moderate predictive ability. Overall, our calibration model successfully estimates soil carbon and nitrogen based on the RPD metric for all sites without the application of spectral pre-treatment methods. Validation outcomes were similar across methods. However validation using 
independent samples is a more robust test of the predictive capacity of the calibration model for estimating soil $\mathrm{C}$ and $\mathrm{N}$.

The estimation of carbon in all four data sets was consistently more successful than the estimation of nitrogen. The high accuracy of SOC estimation results from the strong absorption of OM in the visible-range. Some soil N can be estimated due to functional groups existing in the spectra that are directly related to $\mathrm{N}$ (Kusumo, Hedley, Hedley, \& Tuohy, 2011). In our analysis, the estimation of nitrogen appears to be largely indirect, and mostly due to the relationship of nitrogen with soil carbon. The relationship between measured soil nitrogen and carbon and the resulting $\mathrm{R}^{2}$ validation metrics clarify the mechanism of nitrogen estimation. Correlation coefficient (r) values between nitrogen and carbon were $0.84,0.75,0.74$, and 0.70 for organic soil of the old-growth stand (W8-organic), mineral soil of the harvested stand (W7-mineral), organic soil of the harvested stand (W7-organic), and mineral soil of the old-growth stand (W8-mineral), respectively. The highest $\mathrm{R}^{2}$ value for nitrogen estimation was obtained for the data set of W8-organic $\left(\mathrm{R}^{2}=0.84\right)$, followed by W7-mineral $\left(\mathrm{R}^{2}=0.81\right)$, W7-organic $\left(\mathrm{R}^{2}=\right.$ $0.75)$ and $\mathrm{W} 8$-mineral $\left(\mathrm{R}^{2}=0.73\right)$. The validation $\mathrm{R}^{2}$ values and correlation coefficients paralleled each other, indicating that the estimation of nitrogen was indirect and due to its relationship to carbon.

Earlier studies using the PLSR methodology have likewise obtained successful estimation $\left(R^{2}>0.75\right)$ of soil carbon and nitrogen, though these studies used larger data sets for model calibration relative to our analysis (McCarty, Reeves, Reeves, Follett, \& Kimble, 2002; Morón \& Cossolino, 2002; Dunn et al., 2002). In our study, soil $\mathrm{C}$ and $\mathrm{N}$ were successfully estimated using fewer than 100 calibration samples, an outcome similar to more recent studies (Vasques et al., 2008; Kusumo et al., 2011; Bartholomeus et al., 2008).

\section{Conclusions}

Our analysis applied outcomes from combustion methods for assessing total soil $\mathrm{C}$ and $\mathrm{N}$ concentrations to develop spectral libraries of soil $\mathrm{C}$ and $\mathrm{N}$ using VNIR analysis and the PLSR methodology for model development. Our analysis demonstrated that VNIR methodologies are reliable for estimating soil $\mathrm{C}$ and $\mathrm{N}$ concentrations in soils from managed and old-growth PNW Douglas-fir forest stands. We found that calibration models using separate soil horizon spectra, as well as models using combined horizon spectra, successfully predicted total soil $\mathrm{C}$ and $\mathrm{N}$ concentrations. While the PLSR models were most accurate when applied to soils of a similar stand age, the models demonstrated moderate reliability in predicting total soil $\mathrm{C}$ and $\mathrm{N}$ when applied to different aged stands. Given interest in land management that supports increased SOC sequestration, monitoring carbon storage in forest ecosystems will require the integration of observations and modeling tools. Overall, our spectral library can be a robust and inexpensive method for estimating soil $\mathrm{C}$ and $\mathrm{N}$ concentration for application to management of PNW forests.

\section{Acknowledgements}

The authors thank anonymous reviewers and Harold M. van Es for thoughtful comments on an earlier draft of this manuscript.

\section{References}

Bartholomeus, H. M., Schaepman, M. E., Kooistra, L., Stevens, A., Hoogmoed, W. B., \& Spaargaren, O. S. P. (2008). Spectral reflectance based indices for soil organic carbon quantification. Geoderma, 145(1-2), 28-36. http://dx.doi.org/10.1016/j.geoderma.2008.01.010

Bendor, E., \& Banin, A. (1995a). Near-infrared analysis (NIRA) as a method to simultaneously evaluate spectral $\begin{array}{lllll}\text { featureless constitutes in soils. Soil } & \text { Science, } & 159(4), & \text { 259-270. }\end{array}$ http://dx.doi.org/10.1097/00010694-199504000-00005

Bendor, E., \& Banin, A. (1995b). Near-infrared analysis as a rapid method to simultaneously evaluate several soil properties. Soil Science Society of America Journal, 59(2), 364-372. http://dx.doi.org/10.2136/sssaj1995.03615995005900020014x

Bierlmaier, F. A., \& McKee, A. (1989). Climatic Summaries and Documentation for the Primary Meteorological Station, H. J. Andrews Experimental Forest, 1972 to 1984. USDA Forest Service General Technical Report. $P N W-G T R-242$.

Bilgili, A. V., Akbas, F., \& van Es, H. M. (2011). Combined use of hyperspectral VNIR reflectance spectroscopy and kriging to predict soil variables spatially. Precision Agriculture, 12(3), 395-420. http://dx.doi.org/10.1007/s11119-010-9173-6 
Bilgili, A. V., van Es, H. M., Akbas, F., Durak, A., \& Hively, W. D. (2010). Visible-near infrared reflectance spectroscopy for assessment of soil properties in a semi-arid area of Turkey. Journal of Arid Environments, 74(2), 229-238. http://dx.doi.org/10.1016/j.jaridenv.2009.08.011

Brown, D. J., Shepherd, K. D., Walsh, M. G., Mays, M. D., \& Reinsch, T. G. (2006). Global soil characterization with VNIR diffuse reflectance spectroscopy. Geoderma, 132(3-4), 273-290. http://dx.doi.org/10.1016/j.geoderma.2005.04.025

Burrough, P. A. (1983). Multiscale Sources of Spatial Variation in Soil .1. the Application of Fractal Concepts to Nested Levels of Soil Variation. Journal of Soil Science, 34, 577-597. http://dx.doi.org/10.1111/j.1365-2389.1983.tb01057.x

Chang, C. W., Laird, D. A., Mausbach, M. J., \& Hurburgh, C. R. (2001). Near-infrared reflectance spectroscopy-principal components regression analyses of soil properties. Soil Science Society of America Journal, 65(2), 480-490. http://dx.doi.org/10.2136/sssaj2001.652480x

Chen, J. Q., Franklin, J. F., \& Spies, T. (1992). Vegetation Responses to Edge Environments in Old-Growth Douglas-Fir Forests. Ecological Applications, 2, 387-396. http://dx.doi.org/10.2307/1941873

Chen, J. Q., Franklin, J. F., \& Spies, T. (1993). Contrasting Microclimates among Clear-Cut, Edge, and Interior of Old-Growth Douglas-Fir Forest. Agricultural and Forest Meteorology, 63, 219-237. http://dx.doi.org/10.1016/0168-1923(93)90061-L

Daniel, K. W., Tripathi, N. K., Honda, K., \& Apisit, E. (2004). Analysis of VNIR (400-1100 nm) spectral signatures for estimation of soil organic matter in tropical soils of Thailand. International Journal of Remote Sensing, 25(3), 643-652. http://dx.doi.org/10.1080/0143116031000139944

Dunn, B. W., Beecher, H. G., Batten, G. D., \& Ciavarella, S. (2002). The potential of near-infrared reflectance spectroscopy for soil analysis - a case study from the Riverine Plain of south-eastern Australia. Australian Journal of Experimental Agriculture, 42(5), 607-614. http://dx.doi.org/10.1071/ea01172

Dyrness, C. T., \& Hawk, G. (1972). Vegetation and soils of the Hi-15 Watersheds, H.J. Andrews Experimental Forest. Internal Report 43. Forest Sciences Laboratory, Oregon State University.

Dyrness, C. T., Norgren, J., Sollins, P., \& Vance-Borland, K. (1996). Soil descriptions and data for soil profiles in the Andrews Experimental Forest, selected reference stands, RNA's, and National Park. Carbon and Nutrients Dataset SP001. Retrieved March 7, 2016, from http://www.fsl.orst.edu/lter/data

Fahey, T. J., Woodbury, P. B., Battles, J. J., Goodale, C. L., Hamburg, S. P., Ollinger, S. V, \& Woodall, C. W. (2010). Forest carbon storage: Ecology, management, and policy. Frontiers in Ecology and the Environment, 8(5), 245-252. http://dx.doi.org/10.1890/080169

Franklin, J., \& Forman, R. (1987). Creating landscape patterns by forest cutting: Ecological consequences and principles. Landscape Ecology, 1, 5-18. http://dx.doi.org/10.1007/BF02275261

Fung, I. Y., Tucker, C. J., \& Prentice, K. C. (1987). Application of advanced very high-resolution radiometer vegetation index to study atmosphere-biosphere exchange of $\mathrm{CO}_{2}$. Journal of Geophysical Research-Atmospheres, 92(D3), 2999-3015. http://dx.doi.org/10.1029/JD092iD03p02999

Galloway, J. N., \& Cowling, E. B. (2002). Reactive nitrogen and the world: 200 years of change. Ambio, 31(2), 64-71. http://dx.doi.org/10.1579/0044-7447-31.2.64

Galvao, L. S., \& Vitorello, I. (1998). Variability of laboratory measured soil lines of soils from southeastern Brazil. Remote Sensing of Environment, 63(2), 166-181. http://dx.doi.org/10.1016/s0034-4257(97)00135-1

Goodale, C. L., Apps, M. J., Birdsey, R. A., Field, C. B., Heath, L. S., Houghton, R. A., ... Shvidenko, A. Z. (2002). Forest carbon sinks in the Northern Hemisphere. Ecological Applications, 12(3), 891-899. http://dx.doi.org/10.2307/3060997

Griffiths, R. P., \& Swanson, A. K. (2001). Forest soil characteristics in a chronosequence of harvested Douglas-fir forests. Canadian Journal of Forest Research-Revue Canadienne De Recherche Forestiere, 31(11), 1871-1879. http://dx.doi.org/10.1139/cjfr-31-11-1871

Heyerdahl, E., Swanson, F. J., Berry, D., \& Agee, J. K. (1994). Fire history database of the western United States. Disturbance Dataset DF005. Retrieved March 7, 2016, from http://www.fsl.orst.edu/lter/data 
Homann, P. S., Bormann, B. T., \& Boyle, J. R. (2001). Detecting treatment differences in soil carbon and nitrogen resulting from forest manipulations. Soil Science Society of America Journal, 65(2), 463-469. http://dx.doi.org/10.2136/sssaj2001.652463x

Hudiburg, T., Law, B., Turner, D. P., Campbell, J., Donato, D. C., \& Duane, M. (2009). Carbon dynamics of Oregon and Northern California forests and potential land-based carbon storage. Ecological Applications, 19(1), 163-180. http://dx.doi.org/10.1890/07-2006.1

Hutyra, L. R., Yoon, B., \& Alberti, M. (2011). Terrestrial carbon stocks across a gradient of urbanization: A study of the Seattle, WA region. Global Change Biology, 17(2), 783-797. http://dx.doi.org/10.1111/j.1365-2486.2010.02238.x

Idowu, O. J., van Es, H. M., Abawi, G. S., Wolfe, D. W., Ball, J. I., Gugino, B. K., ... Bilgili, A. V. (2008). Farmer-oriented assessment of soil quality using field, laboratory, and VNIR spectroscopy methods. Plant and Soil, 307(1-2), 243-253. http://dx.doi.org/10.1007/s11104-007-9521-0

IPCC (Intergovernmental Panel on Climate Change). (2014). In R. K. Pachauri \& L. A. Meyer (Eds.), Climate Change 2014: Synthesis Report. Contribution of Working Groups I, II and III to the Fifth Assessment Report of the Intergovernmental Panel on Climate Change.

Jensen, J. R. (2000). Remote sensing of the environment: An Earth resource perspective. Prentice-Hall., Upper Saddle River, N.J.

Johnson, C. E. (1995). Soil-nitrogen status 8 years after whole-tree clear-cutting. Canadian Journal of Forest Research-Revue Canadienne De Recherche Forestiere, 25(8), 1346-1355. http://dx.doi.org/10.1139/x95-147

Klopatek, J. M. (2002). Belowground carbon pools and processes in different age stands of Douglas-fir. Tree Physiology, 22(2-3), 197-204. http://dx.doi.org/10.1093/treephys/22.2-3.197

Kusumo, B. H., Hedley, M. J., Hedley, C. B., \& Tuohy, M. P. (2011). Measuring carbon dynamics in field soils using soil spectral reflectance: Prediction of maize root density, soil organic carbon and nitrogen content. Plant and Soil, 338(1-2), 233-245. http://dx.doi.org/10.1007/s11104-010-0501-4

Li, H., Franklin, J. F., Swanson, F. J., \& Spies, T. A. (1993). Developing alternative forest cutting patterns-A simulation approach. Landscape Ecology, 8(1), 63-75. http://dx.doi.org/10.1007/bf00129867

Ludwig, B., Khanna, P. K., Bauhus, J., \& Hopmans, P. (2002). Near infrared spectroscopy of forest soils to determine chemical and biological properties related to soil sustainability. Forest Ecology and Management, 171, 121-132. http://dx.doi.org/10.1016/S0378-1127(02)00467-X

McCarty, G. W., Reeves, J. B., Reeves, V. B., Follett, R. F., \& Kimble, J. M. (2002). Mid-infrared and near-infrared diffuse reflectance spectroscopy for soil carbon measurement. Soil Science Society of America Journal, 66(2), 640-646. http://dx.doi.org/10.2136/sssaj2002.6400

Pacala, S. W., Hurtt, G. C., Baker, D., Peylin, P., Houghton, R. A., Birdsey, R. A., ... Field, C. B. (2001). Consistent land- and atmosphere-based US carbon sink estimates. Science, 292(5525), 2316-2320. http://dx.doi.org/10.1126/science. 1057320

Rossel, R. A. V., \& McBratney, A. B. (1998). Laboratory evaluation of a proximal sensing technique for simultaneous measurement of soil clay and water content. Geoderma, 85(1), 19-39. http://dx.doi.org/10.1016/S0016-7061(98)00023-8

Sankey, J. B., Brown, D. J., Bernard, M. L., \& Lawrence, R. L. (2008). Comparing local vs. global visible and near-infrared (VisNIR) diffuse reflectance spectroscopy (DRS) calibrations for the prediction of soil clay, organic C and inorganic C. Geoderma, 148(2), 149-158. http://dx.doi.org/10.1016/j.geoderma.2008.09.019

Shepherd, K. D., \& Walsh, M. G. (2002). Development of reflectance spectral libraries for characterization of soil properties. Soil Science Society of America Journal, 66(3), 988-998. http://dx.doi.org/10.2136/sssaj2002.9880

Solomon, S., Qin, D., Manning, M., Chen, Z., Marquis, M., Averyt, K. B., ... Miller, H. L. (2007). Contribution of Working Group I to the Fourth Assessment Report of the Intergovernmental Panel on Climate Change. Cambridge University Press, Cambridge, United Kingdom.

Summers, D., Lewis, M., Ostendorf, B., \& Chittleborough, D. (2011). Visible near-infrared reflectance spectroscopy as a predictive indicator of soil properties. Ecological Indicators, 11, $123-131$. http://dx.doi.org/10.1016/j.ecolind.2009.05.001 
Terhoeven-Urselmans, T., Michel, K., Helfrich, M., Flessa, H., \& Ludwig, B. (2006). Near-infrared spectroscopy can predict the composition of organic matter in soil and litter. Journal of Plant Nutrition and Soil Science, 169, 168-174. http://dx.doi.org/10.1002/jpln.200521712

Vasques, G. M., Grunwald, S., \& Sickman, J. O. (2008). Comparison of multivariate methods for inferential modeling of soil carbon using visible/near-infrared spectra. Geoderma, 146(1-2), 14-25. http://dx.doi.org/10.1016/j.geoderma.2008.04.007

Vitousek, P. M., Aber, J. D., Howarth, R. W., Likens, G. E., Matson, P. A., Schindler, D. W., ... Tilman, D. (1997). Human alteration of the global nitrogen cycle: Sources and consequences. Ecological Applications, 7(3), 737-750. http://dx.doi.org/10.2307/2269431

Wei, W. W. S. (1990). Time Series Analysis: Univariate and Multivariate Methods. Addison-Wesley Publishing Company, Inc.

\section{Appendix}

\section{Appendix 1}

Abbreviations:

C: carbon; LOOCV: leave-one-out cross-validation; MLR: multiple linear regression; N: nitrogen; PCA: Principal Components Analysis; PLSR: Partial Least Square Regression; PNW: Pacific Northwest; RMSEP: root mean square error of prediction; SOC: soil organic carbon; SOM: soil organic matter; VNIR: visible and near-infrared.

\section{Appendix 2}

Autocorrelation Function:

$$
r_{k}=\frac{\frac{1}{n-k} \times \sum_{i=1}^{n-k}\left(X_{i}-\bar{X}\right)\left(X_{i+k}-\bar{X}\right)}{\frac{1}{n} \times \sum_{i=1}^{n}\left(X_{i}-\bar{X}\right)\left(X_{i}-\bar{X}\right)}
$$

Where,

$n=\#$ of samples;

$k=$ number of sampling locations between comparisons;

$X_{i}=$ sample value;

$\bar{X}=$ sample mean.

Cross-Correlation Function:

$$
r_{x y}=\frac{\frac{1}{n-k} \times \sum_{i=1}^{n-k}\left(X_{i}-\bar{X}\right)\left(Y_{i+k}-\bar{Y}\right)}{\sqrt{\left|\frac{1}{n} \times \sum_{i=1}^{n}\left(X_{i}-\bar{X}\right)\left(X_{i}-\bar{X}\right)\right| \times\left|\frac{1}{n} \times \sum_{i=1}^{n}\left(Y_{i}-\bar{Y}\right)\left(Y_{i}-\bar{Y}\right)\right|}}
$$

Where,

$n=\#$ of samples;

$k=$ number of sampling locations between comparisons;

$X_{i}=$ first data set sample value;

$\bar{X}=$ first data set sample mean;

$Y_{i}=$ second data set sample value;

$\bar{Y}=$ second data set sample mean.

\section{Copyrights}

Copyright for this article is retained by the author(s), with first publication rights granted to the journal.

This is an open-access article distributed under the terms and conditions of the Creative Commons Attribution license (http://creativecommons.org/licenses/by/3.0/). 